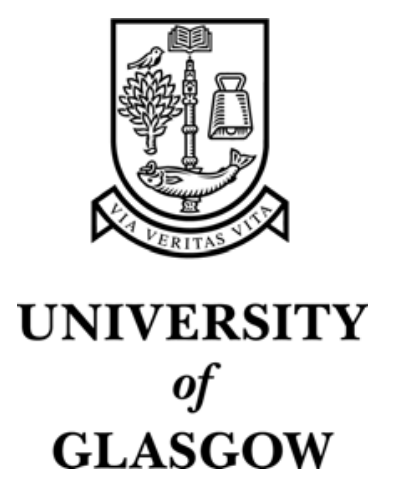

Lindsay, G.M. and Hanlon, W.P. and Smith, L.N. and Belcher, P.R. (2003) Experience of cardiac rehabilitation after coronary artery surgery: effects on health and risk factors. International Journal of Cardiology 87(1):pp. 67-73.

http://eprints.gla.ac.uk/archive/00002825/ 


\title{
EXPERIENCE OF CARDIAC REHABILITATION AFTER CORONARY ARTERY SURGERY: EFFECTS ON HEALTH AND RISK FACTORS
}

\author{
${ }^{+}$Lindsay GM, *Hanlon WP, ${ }^{+}$Smith LN, ${ }^{\$}$ Belcher PR
}

University of Glasgow, Nursing \& Midwifery School ${ }^{+}$, Departments of Cardiac Surgery $\$$ and Public Health*

Corresponding Author:

Dr GM Lindsay

Nursing \& Midwifery School

University of Glasgow

68 Oakfield Avenue

Glasgow G12 8L UK

Tel. $\quad+44(0) 1413306876$

Facs. +44 (0) 1413303539

email gl1z@clinmed.gla.ac.uk

This study was supported by a Research Training Fellowship from the Home and Health Department of the Scottish Office, St Andrew's Square, Edinburgh. 


\section{ABSTRACT}

Objective: Cardiac rehabilitation (CR) programs are provided to support the recovery process following acute myocardial infarction and coronary artery bypass grafting (CABG). Attendance varies. We related attendance following CABG to severity of cardiac symptoms, general health status (Short Form-36) and prevalence of modifiable coronary artery disease (CAD) risk factors.

Methods: 209 patients due to undergo CABG were recruited and assessed preoperatively as well as at a mean of 16.4 months postoperatively. General health status was measured using the Short Form-36 questionnaire. Severity of cardiac symptoms was assessed on a visual analogue scale. Modifiable coronary artery disease risk factors (smoking, body mass index, hypertension and elevated cholesterol) and social deprivation index were noted.

Results: $\quad$. There were ten early and three late deaths. Thirteen patients withdrew consent for investigation therefore 183 were fully studied. $65.0 \%$ of these completed a CR programme and $24.6 \%$ did not attend any programme. $10.4 \%$ partially completed (less than $50 \%$ of time) and were excluded from analysis. Non-attenders were more likely to be smokers $(p=0.002)$, diabetic $(p=0.028)$ and were more from socially deprived geographical areas $(\mathrm{p}=0.013)$, but the proportion of patients with BMI $>25$, BP $>140 / 90$ or cholesterol $>5.0 \mathrm{mMol}^{-1} \mathrm{l}^{-1}$ were the same. There were no differences in age, preoperative NYHA score, number of grafts, angina recurrence (46 \% vs. $38 \%$, p = 0.35) or breathlessness (62 vs. 69\%, $\mathrm{p}=0.40$ ) between attenders and non-attenders. The severity scores of angina ( 2.7 vs. 3.2, $\mathrm{p}=0.286)$ and breathlessness (3.5 vs. 3.6; $\mathrm{p}=0.79$ ) were no different. However, four of the eight health domains measured showed 
significantly better values for attenders than non-attenders; namely: general health (60 vs. $46 \%, \mathrm{p}=0.001$ ), physical function (64 vs. $51 \% \mathrm{p}=0.01$ ), role limitation physical (48 vs. $29 \%$; $\mathrm{p}=0.02$ ) and social function 74 vs. $62 \%, \mathrm{p}=0.04$ ).

Conclusions: This is the first report using SF 36 to evaluate benefits from attending CR. Higher general health scores (SF-36) were associated with attendance at CR although CAD risk factors and cardiac symptoms were not improved but this may be due to the long interval between assessments. 


\section{INTRODUCTION}

Cardiac rehabilitation programmes are now widely available to patients after myocardial infarction and following CABG [1]. They are designed to provide a range of lifestyle and medical interventions to reduce coronary mortality and morbidity [2, 3] through the promotion of a healthy lifestyle and reduction in CAD risk factors [4]. They are not standardized and vary widely even within regions.

Another important objective of cardiac rehabilitation is to improve quality of life although evidence supporting this contention is limited [5] and may be related to problems in defining and measuring quality of life. Despite many eligible candidates only a minority participate in cardiac rehabilitation programmes. A study in the West of Scotland reported low uptake and completion rates of approximately $10 \%$ [6], although an uptake rate of $50 \%$ has been reported in the USA [7].

In this study we report on severity of angina and breathlessness symptoms, levels of health and well-being (as measured using the SF-36 questionnaire), and the presence of major modifiable CAD risk factors (smoking, hypertension, hyperlipidaemia, obesity). We examined the relation of these variables to attendance or non-attendance at cardiac rehabilitation programmes following CABG. 


\section{METHODS}

\section{Study Design and Sample Size}

This retrospective observational study was part of a larger study undertaken in one cardiac centre during 1998. A random sample of 209 patients undergoing elective first time CABG was identified. These patients were reviewed four weeks before operation and at an average time of 16.4 months afterwards.

\section{Demographic information, CAD risk factors and CAD symptoms}

A questionnaire was used to collect data on age, sex, and fullness of attendance at a cardiac rehabilitation programme. Demographic details (age, sex, postcode) were used to estimate socio-economic status using an updated version of Carstairs and Morris deprivation scores [8]. The deprivation score is based on vital statistics collected by UK Government surveys and are calculated using the following indicators of disadvantage: lack of car ownership, male unemployment and overcrowding. Tobacco smoking habit was recorded. Body mass index, blood pressure and cholesterol levels were measured according to standard procedures [9]. Patients were asked to rate the severity of angina and breathlessness using two visual analogue seven point scales which are similar to scales used in other studies [10,11]. The visual analogue rating scale used was a horizontal line anchored at each end by terms that represent the extremes of symptoms experienced. The explanatory details for completion were brief and simple. They were scored on two self-rating scales ranging from zero to seven where zero represented 'no effect on your overall well-being and health' and seven represented 'complete disability, discomfort and restriction to life'. 


\section{SF-36 Questionnaire}

The SF-36 questionnaire (UK standard version) is a thirty-six item scale that generates scores for eight dimensions of health namely: physical functioning, role limitation due to physical health problems, bodily pain, general health, energy and vitality, social functioning, mental health and role limitations due to mental health problems [12]. The scores for each domain range from 0 to 100 with 0 the worst and 100 the best possible health status.

\section{Analysis}

Differences in the outcome variables were tested in relation to attendance or nonattendance at CR using Fisher exact or $\chi^{2}$ tests for categorical variables and Student's t or Mann-Whitney tests for continuous variables by use of Arcus Quickstat Biomedical software (Addison Wesley Longman trading as Research Solutions, UK). The sample size allowed sufficient statistical power to detect a 10\% change in the SF 36 scores with a confidence level of $90 \%$ and a p value of 0.05 . The influence of social deprivation was examined using Fisher exact tests.

\section{RESULTS}

\section{Response rate and follow-up}

Through contact with patients' general practitioners and, where necessary, tracing patient 
records to the relevant Health Board, information about survival status of the study patients was $100 \%$ complete. Of the 209 patients entered prospectively into the study, two were not operated on, ten died within 30 days of operation. and It was established that 196 patients were alive 16.4 months after operation and that three patients (two males; one female) had died in that period. Thirteen refused to be restudied. Follow-up assessments were completed in 183 patients, i.e. $92 \%$ of the original 199 patients who survived operation. Figures in text and tables refer to these 183 completely followed up subjects. Patients were invited to attend a cardiac rehabilitation programme at times ranging from eight to 12 weeks after operation at their local referring cardiac centre; although CABG was performed at one regional cardiac surgical centre, the seven individual programmes varied in content and duration but all programmes were a minimum of eight weeks duration.

\section{Attendance Rates}

Most of these 183 patients, 119 (65.0 \%) attended a cardiac rehabilitation programme, 19 (10.4 \%) attended for less than $50 \%$ of the programme and 45 (24.6 \%) patients did not attend cardiac rehabilitation. Patients who only partly attended rehabilitation were excluded from further analysis. The mean age of attenders was $57.9 \pm 6.8$ years and that of non-attenders $57.9 \pm 9.3$ years $(\mathrm{p}=0.6312)$. The ratio of male attenders to nonattenders was $74.3: 25.7 \%$ and for females was $66.6: 33.3 \%(p=0.3520)$. NYHA scores for attenders 2.500 .52 vs. 2.590 .55 for non-attenders $(\mathrm{p}=0.3630)$ and numbers of grafts were comparable (3.25 0.91 vs. $3.18 \quad 0.88 ; \mathrm{p}=0.9497$ ). Reasons for nonattendance were provided by 23 (51.0 \%) of these patients and were as follows: 'not 
invited' ( $\mathrm{n}=3)$, 'didn't like the programmes' $(\mathrm{n}=2)$, 'couldn't do exercises' $(\mathrm{n}=3)$, 'transport problems' $(\mathrm{n}=4)$, 'ill-health' $(\mathrm{n}=7)$, 'did exercises at home' $(\mathrm{n}=3)$ and returned to work $(\mathrm{n}=1)$.

\section{Effect of Socio-Economic Deprivation}

The proportion of patients in different deprivation categories was compared between those who fully attended and non-attenders; there was no significant difference $(\mathrm{p}=$ 0.104). The percentage of patients attending and not attending in each of the seven deprivation categories are presented in the Figure 1. Analysis of major modifiable risk factors within these groups detected no consistent differences. Minor differences in total cholesterol were seen between deprivation category 4 and 6 patients $(p=0.253)$ but not against other groups. Group 5 patients had greater BMI compared to Group 1 and 4 patients ( $\mathrm{p}=0.0219$ and 0.0146 respectively). No differences of any kind were detected for pre- or post-operative systolic or diastolic blood pressure, breathlessness and angina scores.

In view of the small numbers in each group (see Figure 1) we split the data at the median point of the deprivation scores and compared the attendance rate as well as the prevalence of uncorrected preoperative or postoperative risk factors. Patients who had deprivation scores less than the median (i.e. less deprived) were more likely to have attended rehabilitation than those with scores equal to or greater than the median $(\mathrm{p}=$ 0.013). Uncorrected cardiovascular risk factors were present in virtually equal proportions in both groups irrespective of deprivation category or attendance at 
rehabilitation. 


\section{Cardiac Symptoms}

There was no significant difference in recurrent angina or symptoms of breathlessness between the two groups $(\mathrm{p}=0.138)$; see Table 1 . Similarly, for patients who reported symptoms, the severity of these was not different in attenders compared to non-attenders (Table 1).

\section{Modifiable CAD risk factor status}

The percentage of patients with CAD risk factors that exceeded target levels (smoking, hypertension, hyperlipidaemia, obesity in accordance with current UK guidelines [9]) in attenders and non-attenders at pre-operative and post-operative assessments are presented in Table 2. Smoking both pre- and post-operatively was more frequent in non-attenders ( $p=0.002$ and 0.0019 respectively). It should be noted that smoking incidence was significantly lower in attenders pre-operatively and did not change following attendance at cardiac rehabilitation. The pre-operative presence of a total cholesterol level $>5.0$ mMol. $\mathrm{l}^{-1}$ was higher in non-attenders $(\mathrm{p}=0.016)$ but this difference was not seen at follow-up. Excessive systolic blood pressure in attenders was actually found to be significantly more common after operation than before $(\mathrm{p}=0.006)$. In non-attenders hypertension was commoner but not significantly so $(\mathrm{p}=0.28)$. The proportion of obese patients (BMI > 25) did not change.

\section{General Health Status (SF-36)}

The SF-36 scores obtained from those patients who had attended and completed a cardiac rehabilitation programme were compared to those who had not attended. The results are 
presented in Table 3. Patients who attended had better health status as measured by the SF-36 scale across all eight health domains. The scores were highly significantly better in the 'general health' domain and significantly higher in the 'physical function', 'role limitation due to physical factors', and 'social function' domains, for attenders compared to non-attenders.

\section{DISCUSSION}

The main findings of this study were that, although symptomatology was no different (Table 1), patients who attended cardiac rehabilitation more commonly had higher postoperative subjective health scores than those patients who did not attend (Table 3). Disquietingly there were no differences in the prevalence of CAD risk factors from before operation as determined at 16.4 months postoperatively; similarly there were no differences observed in incidence of uncorrected risk factors between attenders and nonattenders at rehabilitation programmes.

In the literature, programmes at different centres vary in terms of the combinations of exercise training, healthy lifestyle counselling, health education, spouse or partner support, stress management, their delivery setting (i.e. hospital, community, or homebased) and programme length [13]. Of patients recruited into our study the uptake rate of $65 \%$ was higher than that reported in a previous study from the same geographical area although that study included medical patients [6]. The improvement in general health status scores confirms another study that showed that five years after CABG, more patients who attended cardiac rehabilitation perceived their health and overall life 
situation to be good compared to those who did not attend [7]. Whether this can be attributed to the effect of cardiac rehabilitation per se is doubtful and more likely represents a better motivated group of patients as reflected by the lower prevalence of smoking and lower pre-operative total cholesterol levels (Table 2) similar to the findings of Taylor et al [14]. The influence of socio-economic status is discussed later. It has previously been suggested that CAD risk factor management could be improved across the primary to secondary care interface as well as between the different professional groups looking after patients undergoing coronary artery bypass grafting [15]. We cannot confirm that this is occurring. In the present study, no improvement in modifiable CAD risk factors was seen in those who attended rehabilitation. Indeed there was a significant rise in systolic blood pressure seen in the rehabilitation attenders; this was likely to have been due to withdrawal of anti-angina drugs and this is equally likely in both groups. The main point is that it illustrates poor continuity of care in the control of modifiable CAD risk factors by the programmes currently in use. This may be attribute to the stand-alone nature of rehabilitation programmes, which do not have the direct input of the operating surgeon, referring cardiologist or the individual's general practitioner.

Improvement in lifestyle factors of smoking, exercise and body weight can have a significant effect on the reduction of coronary events following acute myocardial infarction $[16,17,18]$. The results from the present study suggest scope for improvement in the management of CAD risk factors and confirm similar inadequate management of preventive health care as highlighted in the large EUROASPIRE study [19]. The continued effect of uncorrected CAD risk factors has been shown to be related to the 
progression of atherosclerosis in both graft and native coronary vessels [20]. The disappointing persistence of smoking habit in rehabilitation attenders as well as nonattenders testifies to the difficulty of curbing this habit and although smokers were less likely to attend it is doubtful whether that aspect of their behaviour would have been modified. Similar observations could be made for BMI. Of the medically managed risk factors the worse hypertension seen in attenders at the follow up visit was surprising and may indicate fewer attendances at their doctor due to perceived better health as documented by their improved SF-36 scores.

There was no difference in the incidence or severity of angina or breathlessness between attenders and non-attenders at cardiac rehabilitation (Table 1), confirming results from another study that examined outcome after myocardial infarction in relation to attendance at cardiac rehabilitation [7]. Interestingly there was a higher incidence of diabetes among the non-attenders but it is hard to work out what influence this might have. The high incidence of reported symptoms in both attenders and non-attenders may reflect the subjective nature of the assessment although it is the patients' perception that is recorded. The correlation with CCC and NYHA scores has not been made although postoperatively the angina and dyspnoea scores were less severe as previously reported [21].

A mixed picture of attendance patterns in relation to socio-economic group was evident (Figure 1). In the highest socio-economic groups (one and two) more patients did not attend compared to those who did attended, although these groups were small. Highest attendance rates occurred in deprivation categories 3, 4 and 7. Moving from the highest 
to lowest socio-economic groups showed a trend of increased non-attendance but did not reach statistical significance. Splitting the patients by individual deprivation category produced almost no significant between-group differences which either confirms the heterogeneity of our population or the effect of small group numbers. Therefore when these data were split about the median, non-attendance was associated with higher social deprivation scores. Other research has shown that individuals from areas of high socioeconomic deprivation are less likely to attend cardiac rehabilitation programmes [6,22]. Taylor et al. [14] showed a strong relationship between high levels of socioeconomic deprivation and smoking with non-attendance at cardiac rehabilitation following coronary artery bypass grafting (CABG). We have confirmed these associations in our study. In addition we have found a similar attendance rate at 65\% compared to 59\% [14]. In view of the National Service Framework [23] target of attendance levels of $85 \%$ of all eligible patients, representing a $20 \%$ increase in activity, it is important that we can justify the necessary investment with contemporary data on the likely benefits to health from attendance at cardiac rehabilitation.

We have shown that although general health status, as assessed by the short form 36 questionnaire was improved in patients who attended cardiac rehabilitation compared to those who did not, there was no difference in uncorrected CHD risk factors or levels of cardiac symptoms. We also noted that, despite attendance being associated with less deprivation, the incidence or re-emergence of cardiovascular risk factors was virtually equal across the board, suggesting a homogeneous population in terms of biomedical markers of disease. 


\section{Limitations}

These results must be interpreted with caution because the study was observational in design. Also because of the disability, present preoperatively, the SF-36 score was only measured at follow-up. Thus we cannot be sure that the group who attended cardiac rehabilitation did not have different preoperative characteristics from those patients who did not attend. It is possible that those patients who attended rehabilitation were a selfselected group with better education and motivation and thus the observed differences in health status could be explained. This is only supported by the fewer smokers among those who attended but not by the deprivation category data and the presence of uncorrected risk factors for cardiovascular disease across the board. The angina and dyspnoea scores were subjective and were not backed up by an objective assessment such as exercise testing although most symptomatic patients reported an improvement on preoperative scores.

At first sight the influence of rehabilitation appears disappointing. However the follow up assessments occurred about 10 months after completion of the programmes during which time the positive messages had been vitiated and early benefits had receded.

\section{Conclusions}

The majority of patients attended cardiac rehabilitation. There was no difference between attenders and non-attenders in the presence of uncorrected CAD risk factors, angina or breathlessness, or level of symptoms, if present. However, patients who attended cardiac rehabilitation had better health status as measured by the SF-36 scale across all eight 
health domains which were most striking in the general health, physical function, physical role limitation and social function domains, although we cannot be sure that this did not pertain before operation. Our poor performance in improving coronary risk factors suggests a failure in continuity of care and possibly need for more extensive cardiac rehabilitation, which may require major organisational changes. 


\section{REFERENCES}

1. Thompson DR, Bowman GS, Kitson AL, de Bono DP, Hopkins A. Cardiac rehabilitation services in England and Wales: a national survey. Int $\mathrm{J}$ Cardiol 1997;59:299-304.

2. Jolliffe JA, Rees K, Taylor RS, Thompson D, Oldridge N, Ebrahim S. Exercise-based rehabilitation for coronary heart disease (Cochrane Review). In: The Cochrane Library, Issue 3, 2001. Oxford:

3. O'Connor GT, Buring JE, Yusuf S, Goldhaber SZ, Olmstead EM and Paffenbarger RS. An overview of randomised trials of rehabilitation with exercise after myocardial infarction. Circulation 1989;80:234-44.

4. Moher M, Schofield T, Weston S, Fullard E. Managing established coronary heart disease. Br Med J 1997;314:69-70.

5. Pell J. Cardiac rehabilitation: a review of its effectiveness. Coronary Health Care 1997;1:8-17.

6. Pell J, Morrison C, Blatchford O, Pell A, Dargie H. Retrospective study of influence of deprivation on uptake of cardiac rehabilitation. Br Med J 1996;313:267-8.

7. Evenson KR, Rosamond WD, Luepker RV. Predictors of outpatient cardiac rehabilitation utilization: the Minnesota Heart Surgery Registry. J Cardiopulm Rehab 1998;18:192-8.

8. Carstairs V, Morris R. Deprivation and health in Scotland. Aberdeen: Aberdeen University Press. 1991. 
9. Wood D, Durrington P, Poulter N, McInnes G, Rees A and Wray R on behalf of the Societies. Joint British Recommendations on prevention of coronary heart disease in clinical practice. Heart 1998;80(Suppl2):S1-29.

10. Scott J, Huskisson E C. Graphic representation of pain. Pain 1976;2:175-84.

11. Huskisson E C. Measurement of pain. J Rheumatol 1982;9:768-9.

12. Stewart AL, Ware JE. Measuring functioning and wellbeing: the medical outcomes study. London: Duke University Press, 1992.

13. Thompson DR. Cardiac rehabilitation services: the need to develop guidelines. Quality in Health Care 1994;3:169-72.

14. Taylor FC, Victory JJ, Angelini GD Use of cardiac rehabilitation among patients following coronary artery bypass surgery. Heart 2001;86:91-93.

15. McHugh F, Lindsay GM, Hanlon P, Hutton I, Brown MR, Morrison C, Wheatley DJ Nurse-led shared care for patients on the waiting list for CABG: a randomised controlled trial Heart, 2001;86:317-23.

16. de Lorgeril M, Renaud S, Mamelle N. Mediterranean alpha-linolenic acid-rich diet in secondary prevention of coronary heart disease. Lancet 1994;343:1454-9.

17. Burr ML, Fehily AM, Gilbert JF. Effects of changes in fat, fish and fibre intakes on death and myocardial infarction: Diet and Reinfarction Trial (DART). Lancet 1989;ii:757-61.

18. Wilhelmsson C. Epidemiology of smoking and intervention studies of smoking. Am Heart J 1988;115:242-9.

19. EUROASPIRE. A European Society of Cardiology survey of secondary prevention of coronary heart disease: Principal results. EUROASPIRE Study Group. European 
Action on Secondary Prevention through Intervention to Reduce Events. Eur Heart J 1996;75:334-42.

20. Lindsay G M, Smith LN, Hanlon P, Wheatley D J The influence of general health status and social support on symptomatic outcome following coronary artery bypass grafting. Heart 2001;85:80-86.

21. Lytle BW. The clinical impact of atherosclerotic saphenous vein to coronary artery bypass grafts. Semin Thorac Cardiovasc Surg 1994;6:81-6.

22. Harlan WR, Sandler SA, Lee KL, Lam LC and Mark DB. Importance of baseline functional and socioeconomic factors for participation in cardiac rehabilitation. Am J Cardiol 1995;76:36-9.

23. Department of Health. National service framework for coronary heart disease. London: HMSO, 2000. Department of Health. National service framework for coronary heart disease. London: HMSO, 2000. 
Percentage Attendance and Non-attendance at Cardiac Rehabilitation by Deprivation Category 
Table 1 Post-operative Incidence of Angina and Breathlessness Including Severity by Self-Assessment Using a 7 Point Scale). Relation to Attendance at Cardiac Rehabilitation

\begin{tabular}{|c|c|c|c|}
\hline Symptom & Attenders & p value & Non-attenders \\
\hline Angina - Presence & $46 \%$ & 0.35 & $38 \%$ \\
\hline - Severity & $2.86 \pm 1.60$ & 0.286 & $3.16 \pm 1.67$ \\
\hline - Presence & $62 \%$ & 0.40 & $69 \%$ \\
\hline - Severity & $3.47 \pm 1.79$ & 0.794 & $3.57 \pm 1.87$ \\
\hline
\end{tabular}

The numerical range for angina severity was $0-6$ using a linear analog scale and rounded to the nearest 0.5 . A score of 0.5 indicates minimal angina. The range of severity for breathlessness was 0-7 and was treated similarly.

Definition of severity of both angina and breathlessness was subjective, based on the patients' own assessment and interpretation of symptom severity, and was not confirmed by any objective assessment such as exercise testing. 


\section{Table 2}

\section{Proportion of Patients with CAD Risk Factors Exceeding Target Levels. Relation to Attendance at Cardiac Rehabilitation}

\begin{tabular}{|c|c|c|c|}
\hline Variable & $\begin{array}{r}\text { Attended } \\
(n=119)\end{array}$ & $\begin{array}{l}\text { p (between } \\
\text { group) }\end{array}$ & $\begin{array}{l}\text { Not Attended } \\
(n=44)\end{array}$ \\
\hline $\begin{array}{c}\text { SBP } \geq 140 \text { pre- } \\
\text { vs. } \\
\text { SBP } \geq 140 \text { post- }\end{array}$ & $p=0.006$ & 0.481 & $48 \%$ \\
\hline $\begin{array}{c}\mathrm{DBP} \geq 90 \text { pre- } \\
v s . \\
\mathrm{DBP} \geq 90 \text { post- }\end{array}$ & $\begin{array}{r}33 \% \\
p=0.18 \\
42 \%\end{array}$ & $\begin{array}{l}0.571 \\
0.280\end{array}$ & $\begin{array}{l}27 \% \\
32 \%\end{array}$ \\
\hline $\begin{array}{c}\text { Cholesterol } \geq 200 \text { pre- } \\
\text { vs. } \\
\text { Cholesterol } \geq 200 \text { post- }\end{array}$ & $p=0.10 \%$ & $\begin{array}{l}\mathbf{0 . 0 1 6} \\
0.219\end{array}$ & $\begin{array}{l}48 \% \\
52 \%\end{array}$ \\
\hline $\begin{aligned} \mathrm{BMI} & \geq 25.0 \text { pre- } \\
& v s . \\
\mathrm{BMI} & \geq 25.0 \text { post- }\end{aligned}$ & $p=1 \quad \begin{array}{r}82 \% \\
82 \%\end{array}$ & 0.157 & $\begin{array}{l}91 \% \\
77 \%\end{array}$ \\
\hline $\begin{array}{c}\text { Current Smoker Pre- } \\
\text { vs. } \\
\text { Current Smoker Post- }\end{array}$ & $p=1 \begin{array}{r}14 \% \\
14 \%\end{array}$ & 0.002 & $\begin{array}{l}43 \% \\
39 \%\end{array}$ \\
\hline
\end{tabular}

SBP systolic blood pressure (mmHg)

DBP diastolic blood pressure (mmHg)

Cholesterol $=$ total cholesterol (mg\%). In Europe this is expressed as $\mathrm{mM}$ per liter and converts to $\mathrm{mg} \%$ by a factor of 38.7 . Our target value of $5 \mathrm{mM} . \mathrm{l}^{-1}$ has been rounded to $200 \mathrm{mg} \%$

BMI body mass index

Bold type indicates significant between group difference by unpaired t-test

pre- represents pre-operative levels.

post- represents post-operative levels.

vs. $\quad$ p value from paired t-tests comparing pre- and post-operative values. Significant $\mathrm{p}$ values in bold italic font. 


\section{Table 3}

\section{Proportion of Patients with CAD Risk Factors Exceeding Target Levels. Relation to Attendance at Cardiac Rehabilitation}

\begin{tabular}{|c|c|c|c|}
\hline Variable & $\begin{array}{r}\text { Attended } \\
(n=119)\end{array}$ & $\begin{array}{l}\text { p (between } \\
\text { group) }\end{array}$ & $\begin{array}{l}\text { Not Attended } \\
(n=44)\end{array}$ \\
\hline $\begin{array}{c}\text { SBP } \geq 140 \text { pre- } \\
\text { vs. } \\
\text { SBP } \geq 140 \text { post- }\end{array}$ & $p=0.006$ & 0.481 & $48 \%$ \\
\hline $\begin{array}{c}\mathrm{DBP} \geq 90 \text { pre- } \\
v s . \\
\mathrm{DBP} \geq 90 \text { post- }\end{array}$ & $\begin{array}{r}33 \% \\
p=0.18 \\
42 \%\end{array}$ & $\begin{array}{l}0.571 \\
0.280\end{array}$ & $\begin{array}{l}27 \% \\
32 \%\end{array}$ \\
\hline $\begin{array}{c}\text { Cholesterol } \geq 200 \text { pre- } \\
\text { vs. } \\
\text { Cholesterol } \geq 200 \text { post- }\end{array}$ & $p=0.10 \%$ & $\begin{array}{l}\mathbf{0 . 0 1 6} \\
0.219\end{array}$ & $\begin{array}{l}48 \% \\
52 \%\end{array}$ \\
\hline $\begin{aligned} \mathrm{BMI} & \geq 25.0 \text { pre- } \\
& v s . \\
\mathrm{BMI} & \geq 25.0 \text { post- }\end{aligned}$ & $p=1 \quad \begin{array}{r}82 \% \\
82 \%\end{array}$ & 0.157 & $\begin{array}{l}91 \% \\
77 \%\end{array}$ \\
\hline $\begin{array}{c}\text { Current Smoker Pre- } \\
\text { vs. } \\
\text { Current Smoker Post- }\end{array}$ & $p=1 \begin{array}{r}14 \% \\
14 \%\end{array}$ & 0.002 & $\begin{array}{l}43 \% \\
39 \%\end{array}$ \\
\hline
\end{tabular}

SBP systolic blood pressure (mmHg)

DBP diastolic blood pressure (mmHg)

Cholesterol $=$ total cholesterol (mg\%). In Europe this is expressed as $\mathrm{mM}$ per liter and converts to $\mathrm{mg} \%$ by a factor of 38.7 . Our target value of $5 \mathrm{mM} . \mathrm{l}^{-1}$ has been rounded to $200 \mathrm{mg} \%$

BMI body mass index

Bold type indicates significant between group difference by unpaired t-test

pre- represents pre-operative levels.

post- represents post-operative levels.

vs. $\quad$ p value from paired t-tests comparing pre- and post-operative values. Significant $\mathrm{p}$ values in bold italic font. 


\section{Table 4}

\section{Comparison of Mean \pm SD SF - 36 Scores between Non- attenders versus Full Attenders at Postoperative Assessment}

\begin{tabular}{|c|c|c|c|c|}
\hline $\begin{array}{l}\text { SF-36 } \\
\text { domains } \\
\text { (Normal values) }\end{array}$ & $\begin{array}{l}\text { time } \\
\text { point }\end{array}$ & $\begin{array}{l}\text { Attender } \\
(n=114)\end{array}$ & $\mathbf{p}$ & $\begin{array}{c}\text { Non-attender } \\
(n=41)\end{array}$ \\
\hline $\begin{array}{l}\text { Bodily } \\
\text { pain } \\
(79 \pm 24)\end{array}$ & $\begin{array}{c}\text { pre } \\
p \\
\text { post }\end{array}$ & $\begin{array}{c}45.526 .1 \\
<0.0001 \\
65.0 \pm 28.5\end{array}$ & $\begin{array}{l}0.4907 \\
0.1750\end{array}$ & $\begin{array}{c}41.724 .8 \\
\mathbf{0 . 0 1 7 0} \\
57.8 \pm 28.4\end{array}$ \\
\hline $\begin{array}{l}\text { Energy/ } \\
\text { vitality } \\
(63 \pm 20)\end{array}$ & $\begin{array}{c}\text { pre } \\
p \\
\text { post }\end{array}$ & $\begin{array}{l}37.121 .9 \\
<0.0001 \\
50.9 \pm 24.3\end{array}$ & $\begin{array}{l}0.0589 \\
\mathbf{0 . 0 1 7 9}\end{array}$ & $\begin{array}{c}29.618 .2 \\
\mathbf{0 . 0 4 7 6} \\
40.2 \pm 20.4\end{array}$ \\
\hline $\begin{array}{l}\text { General } \\
\text { health } \\
(68 \pm 23)\end{array}$ & $\begin{array}{c}\text { pre } \\
p \\
\text { post }\end{array}$ & $\begin{array}{c}36.917 .4 \\
<0.0001 \\
60.0 \pm 24.0\end{array}$ & $\begin{array}{l}0.1722 \\
\mathbf{0 . 0 0 0 4}\end{array}$ & $\begin{array}{c}32.414 .3 \\
0.0093 \\
44.4 \pm 22.4\end{array}$ \\
\hline $\begin{array}{l}\text { Mental } \\
\text { health } \\
(78 \pm 17)\end{array}$ & $\begin{array}{c}\text { pre } \\
p \\
\text { post }\end{array}$ & $\begin{array}{c}63.418 .5 \\
0.0465 \\
68.2 \pm 19.3\end{array}$ & $\begin{array}{l}\mathbf{0 . 0 2 4 4} \\
0.0986\end{array}$ & $\begin{array}{c}55.119 .5 \\
0.108 \\
62.9 \pm 17.9\end{array}$ \\
\hline $\begin{array}{l}\text { Physical } \\
\text { function } \\
(80 \pm 22)\end{array}$ & $\begin{array}{c}\text { pre } \\
p \\
\text { post }\end{array}$ & $\begin{array}{c}36.923 .7 \\
<0.0001 \\
63.9 \pm 27.2\end{array}$ & $\begin{array}{l}0.376 \\
\mathbf{0 . 0 0 1 5}\end{array}$ & $\begin{array}{c}32.924 .4 \\
\mathbf{0 . 0 1 8 9} \\
46.9 \pm 28.1\end{array}$ \\
\hline $\begin{array}{l}\text { Role: } \\
\text { - emotional } \\
(86 \pm 30)\end{array}$ & $\begin{array}{c}\text { pre } \\
p \\
\text { post }\end{array}$ & $\begin{array}{c}38.644 .0 \\
\mathbf{0 . 0 1 2 0} \\
56.4 \pm 46.4\end{array}$ & $\begin{array}{l}0.7631 \\
0.1611\end{array}$ & $\begin{array}{c}37.043 .5 \\
0.5982 \\
41.4 \pm 44.9\end{array}$ \\
\hline $\begin{array}{l}\text { Role: } \\
\text { - physical } \\
(79 \pm 36)\end{array}$ & $\begin{array}{c}\text { pre } \\
p \\
\text { post }\end{array}$ & $\begin{array}{c}15.431 .6 \\
<0.0001 \\
49.0 \pm 45.8\end{array}$ & $\begin{array}{l}0.5459 \\
\mathbf{0 . 0 3 2 5}\end{array}$ & $\begin{array}{c}8.320 .7 \\
0.0664 \\
28.7 \pm 40.4\end{array}$ \\
\hline $\begin{array}{l}\text { Social } \\
\text { function } \\
(87 \pm 23)\end{array}$ & $\begin{array}{c}\text { pre } \\
p \\
\text { post }\end{array}$ & $\begin{array}{c}50.2 \quad 29.0 \\
<\mathbf{0 . 0 0 0 1} \\
73.9 \pm 27.6\end{array}$ & 0.2574 & $\begin{array}{c}43.527 .0 \\
\mathbf{0 . 0 1 3 7} \\
61.0 \pm 33.5\end{array}$ \\
\hline
\end{tabular}

Range for all domains of SF - 36 questionnaire was 0-100. The normal values under domain name are those for normal people aged 55-64 years. Mean age of patients in the present series was $57.8 \pm 7.6$ years. Statistically significant p values (by ANOVAR) in bold font. 


\section{Figure 1 legend}

The histogram shows the percentage of patients who attended (open bars) or did not attend (shaded bars) a cardiac rehabilitation programme following coronary artery bypass grafting; data are split according to the seven deprivation categories based on postcode areas [8].

$2 \mathrm{x} \mathrm{k} \chi^{2}$ test on relative frequencies:- $\quad$ Total $\chi^{2}=11.51 ; \mathrm{p}=0.0738$

$\chi^{2}$ for linear trend $=-1.53 ; \mathrm{p}=0.125$ 